\title{
Environmental Economics, the Bioeconomy and the Role of Government
}

\author{
Michael Ahlheim
}

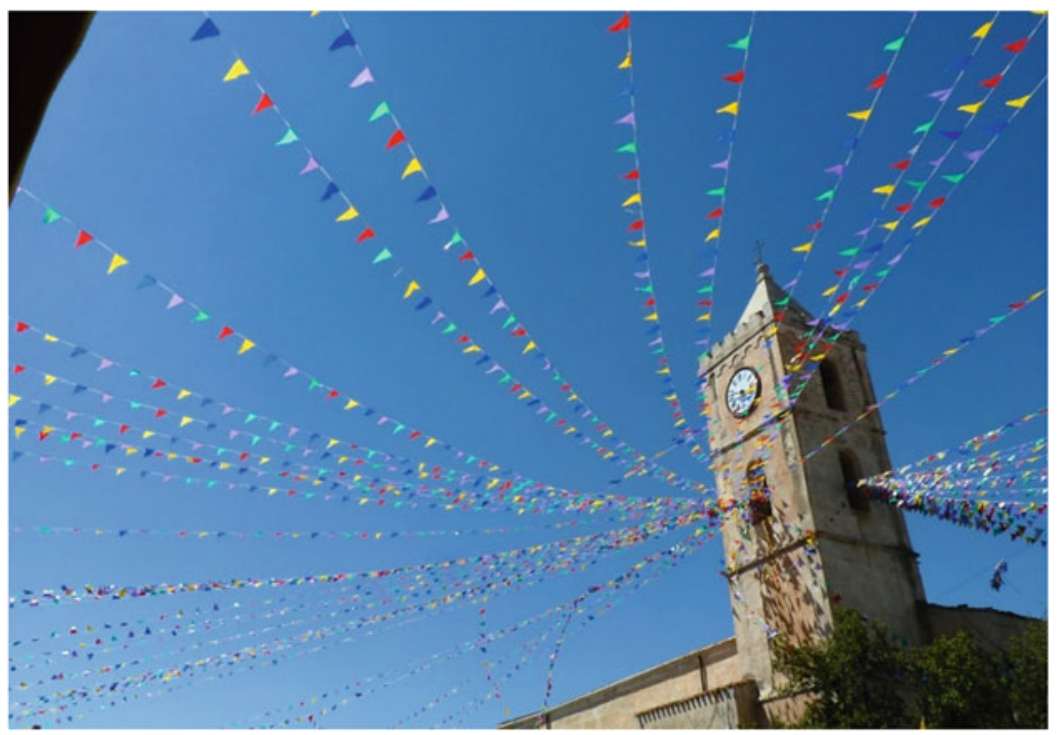

(C) Jürgen Jarosch

\begin{abstract}
The bioeconomy serves the goals of resource saving and of reducing environmental pollution and is, therefore, in accordance with principles of sustainable development. Since private markets alone fail to serve these goals successfully, the government is called for to promote the bioeconomy in order to ensure a sustainable development of the economy.
\end{abstract}

M. Ahlheim ( $\bowtie)$

Institute of Economics; Environmental Economics,

Regulatory and Consumer Policy, University of

Hohenheim, Stuttgart, Germany

e-mail: ahlheim@uni-hohenheim.de 
In this chapter the concept of sustainability, which is essentially an intertemporal concept, is introduced. Thereafter, the basic principles of resource economics, i.e., the optimal use of natural resources over time, are discussed using a simple intertemporal model. Reasons for market failure in the environmental sector are discussed along with various governmental instruments and policies to address the different kinds of market failure.

\section{Keywords}

Social welfare - Utility function - Pareto optimum - Sustainability Market failure - Government policies - Externalities - Public goods • Common-pool goods

\section{Learning Objectives}

After studying this chapter, you should know:

- The main concepts of sustainability

- The optimal exploitation of a nonrenewable resource over time

- The main causes of market failure in an environmental context

- Instruments of government policy in the bioeconomy

\subsection{Introduction}

Article 56 of the German Basic Law states the oath of office that has to be taken by the Federal President, the Federal Chancellor, and the Federal Ministers of the German Government:

I swear that I will dedicate my efforts to the wellbeing of the German people, promote their welfare, protect them from harm, uphold and defend the Basic Law and the laws of the Federation, perform my duties conscientiously, and do justice to all. So help me God. (Art. 56 Basic Law for the Federal Republic of Germany)

Expressed in terms of welfare economics, this means that the government is required to maximize a social welfare function, the arguments of which are the individual utility functions of the citizens of the respective country:

$$
\begin{gathered}
W=w\left(u_{1}\left(x^{1}, z\right), u_{2}\left(x^{2}, z\right), \ldots, u_{H}\left(x^{H}, z\right)\right) ; \\
\left(\frac{\partial w}{\partial u_{h}}>0(h=1,2, \ldots, H)\right)
\end{gathered}
$$

In (10.1), W denotes the level of social welfare, while $\mathrm{w}$ is the welfare function. The (wellbehaved) individual utility functions $u_{\mathrm{h}}$ describe the wellbeing of citizens $h(h=1,2, \ldots, H)$ as strictly monotonically increasing functions of their individual market consumption bundles $x^{h}$ $=\left[x_{1}^{h}, x_{2}^{h}, \ldots, x_{N}^{h}\right]$ and the vector of environmental quality parameters $z=\left[z_{1}, z_{2}, \ldots, z_{L}\right]$ where the parameters $z_{l}(l=1,2, \ldots, L)$ represent, e.g., water quality, air quality, the area covered with forests, the state of biodiversity, etc., which are the same for all citizens. From (10.1), it becomes obvious that if the government wants to maximize social welfare, its main action parameters are the provision of market commodities $x$ and the provision of environmental quality $z$, all other things being constant. This is illustrated in Fig. 10.1. While market goods are produced in the economic sector, environmental quality accrues from the environmental sector. A welfare-maximizing government is responsible for both sectors.

From the first-order conditions of a welfare maximum, it follows that every welfare maximum is also a Pareto optimum, i.e., a state of the economy, where it is not possible to increase 


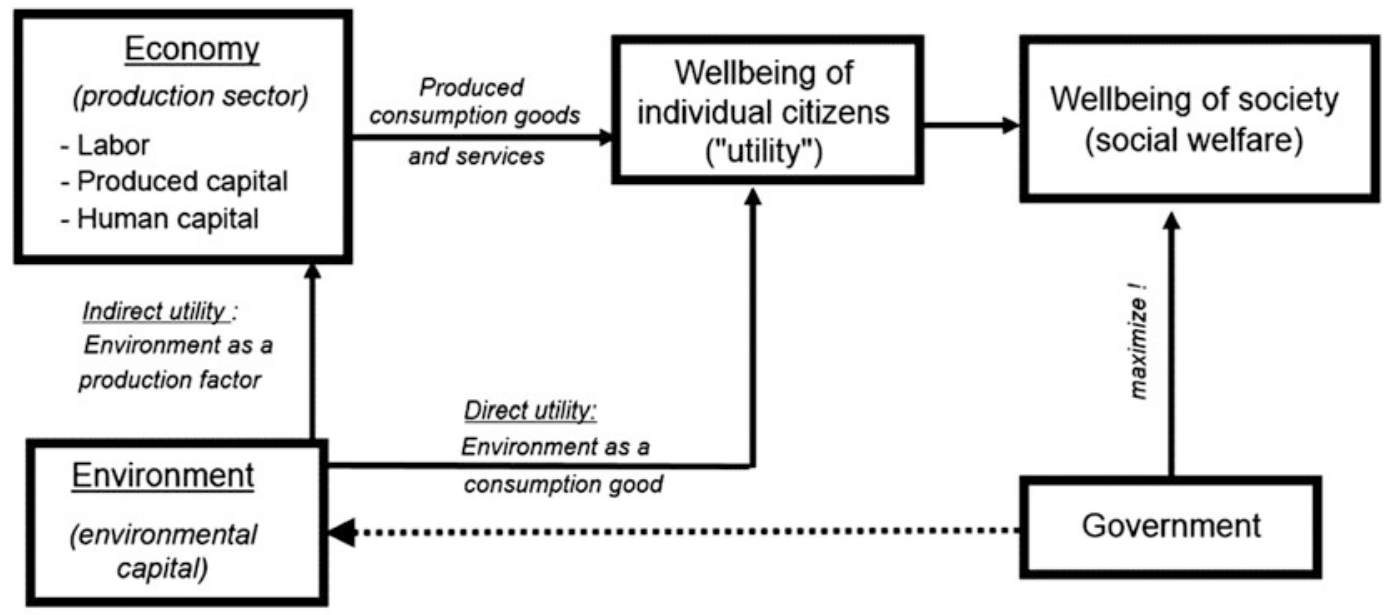

\section{Government is responsible for the environment !}

Fig. 10.1 The role of government

the wellbeing or utility of one individual without reducing the wellbeing or utility of some other individuals (Fig. 10.1), while the inverse implication does not hold. Therefore, a Pareto-optimal allocation of resources in the private as well as in the environmental sector is a necessary, but not sufficient, condition for a welfare maximum. Pareto optimality is a pure efficiency criterion, while a welfare maximum considers also distributional issues as represented by the welfare weights $\partial w / \partial u_{h}$ which describe the relative importance of the wellbeing of a household $h$ from the perspective of the welfaremaximizing government (Fig. 10.2). It should be noted that in Fig. 10.2, it is assumed that the environmental variable $z$ represents a pure public good, i.e., it is rival in consumption, and nobody can be excluded from consuming it.

\section{Rivalry in Consumption and Exclusion Principle}

Rivalry in consumption means that the marginal utility of consuming a rival good decreases if some other person consumes the same good. For non-rival goods like clean air or a beautiful landscape or political leadership or national pride, the (marginal) utility of enjoying these goods is not reduced if others enjoy the same goods.

The exclusion principle holds if the owner of a commodity can exclude others from consuming this commodity. Market commodities like a bottle of water are typical examples of goods where the exclusion principle holds, while public goods like clean air or political leadership are examples of goods where this principle does not hold.

MRS stands for "marginal rate of substitution" and $M R T$ for "marginal rate of transformation." Nonnegative values of the implicit production function $F(\bullet)$ describe the production possibilities of the economy for a given vector $\bar{y}$ of available input quantities. Efficient production requires that $F(\bullet)=0$. To keep the notation simple, the two households are denoted by the indices $A$ and $B$. $L(\bullet)$ is the Lagrangian function, which equals the sum of the objective function $w(\bullet)$, which we want to maximize, and the product of the Lagrangian multiplier $\mu$ and the restriction function $F(\bullet)$. It is 


\section{A welfare maximum implies a Pareto optimum (2 market goods +1 public good):}

$\max w\left(u^{A}\left(x_{1}^{A}, x_{2}^{A}, z\right), u^{B}\left(x_{1}^{B}, x_{2}^{B}, z\right)\right)$

$$
\begin{aligned}
& \text { subject to: } \\
& x_{1}^{A}+x_{1}^{B}=x_{1} \\
& x_{2}^{A}+x_{2}^{B}=x_{2} \\
& F\left(x_{1}, x_{2}, z, \bar{y}\right) \geq 0
\end{aligned}
$$

\section{Lagrangian:}

$$
\begin{aligned}
\mathrm{L}(\bullet)= & w\left(\mathrm{u}^{\mathrm{A}}\left(\mathrm{x}_{1}^{\mathrm{A}}, \mathrm{x}_{2}^{\mathrm{A}}, \mathrm{z}\right), \mathrm{u}^{\mathrm{B}}\left(\mathrm{x}_{1}^{\mathrm{B}}, \mathrm{x}_{2}^{\mathrm{B}}, \mathrm{z}\right)\right) \\
& +\mu \cdot \mathrm{F}\left(\mathrm{x}_{1}, \mathrm{x}_{2}, \mathrm{z}, \overline{\mathrm{y}}\right)
\end{aligned}
$$

\section{$\Rightarrow$ Pareto optimum!}

$$
\begin{aligned}
& \text { Optimality conditions of a welfare maximum: } \\
& \frac{\partial \mathbf{w}}{\partial \mathbf{u}^{\mathrm{A}}} \cdot \frac{\partial \mathbf{u}^{\mathrm{A}}}{\partial \mathbf{x}_{1}^{\mathrm{A}}}=-\mu^{*} \cdot \frac{\partial \mathrm{F}}{\partial \mathbf{x}_{1}}=\frac{\partial \mathbf{w}}{\partial \mathbf{u}^{\mathrm{B}}} \cdot \frac{\partial \mathbf{u}^{\mathrm{B}}}{\partial \mathbf{x}_{1}^{\mathrm{B}}} \\
& \frac{\partial \mathbf{w}}{\partial \mathbf{u}^{\mathrm{A}}} \cdot \frac{\partial \mathbf{u}^{\mathrm{A}}}{\partial \mathbf{x}_{2}^{\mathrm{A}}}=-\mu^{*} \cdot \frac{\partial \mathrm{F}}{\partial \mathbf{x}_{2}}=\frac{\partial \mathbf{w}}{\partial \mathbf{u}^{\mathrm{B}}} \cdot \frac{\partial \mathbf{u}^{\mathrm{B}}}{\partial \mathbf{x}_{2}^{\mathrm{B}}} \\
& \frac{\partial \mathbf{w}}{\partial \mathbf{u}^{\mathrm{A}}} \cdot \frac{\partial \mathbf{u}^{\mathrm{A}}}{\partial \mathbf{z}}+\frac{\partial \mathbf{w}}{\partial \mathbf{u}^{\mathrm{B}}} \cdot \frac{\partial \mathbf{u}^{\mathrm{B}}}{\partial \mathbf{z}}=-\mu^{*} \cdot \frac{\partial \mathbf{F}}{\partial \mathbf{z}} \\
& F\left(x_{1}, x_{2}, z, \bar{y}\right)=0 \\
& \Rightarrow \frac{\partial \mathbf{u}^{\mathrm{A}} / \partial \mathbf{x}_{1}^{\mathrm{A}}}{\partial \mathbf{u}^{\mathrm{A}} / \partial \mathbf{x}_{2}^{\mathrm{A}}}=\frac{\partial \mathbf{F} / \partial \mathbf{x}_{1}}{\partial \mathbf{F} / \partial \mathbf{x}_{2}}=\frac{\partial \mathbf{u}^{\mathrm{B}} / \partial \mathbf{x}_{1}^{\mathrm{B}}}{\partial \mathbf{u}^{\mathrm{B}} / \partial \mathbf{x}_{2}^{\mathrm{B}}} \\
& \underbrace{\underbrace{}_{\mathrm{MRT}_{2,1}}}_{\mathrm{MRS}_{2,1}^{\mathrm{A}}} \underbrace{\mathrm{u}_{\partial \mathrm{A}}}_{\mathrm{MRS}_{2,1}^{\mathrm{B}}} \\
& \Rightarrow \frac{\partial \mathbf{u}^{\mathrm{A}} / \partial \mathbf{z}}{\partial \mathbf{u}^{\mathrm{A}} / \partial \mathbf{x}_{1}^{\mathrm{A}}}+\frac{\partial \mathbf{u}^{\mathrm{B}} / \partial \mathbf{z}}{\partial \mathbf{u}^{\mathrm{B}} / \partial \mathbf{x}_{1}^{\mathrm{B}}}=\frac{\partial \mathbf{F} / \partial \mathbf{z}}{\partial \mathbf{F} / \partial \mathbf{x}_{1}} \\
& \underbrace{\partial \mathrm{M}^{\mathrm{A}} / \partial \mathrm{x}_{1}^{\mathrm{A}}}_{\mathrm{MRS}_{1,2}^{\mathrm{A}}} \underbrace{\mathrm{u}^{\mathrm{B}} / \partial \mathrm{x}_{1}^{\mathrm{B}}}_{\mathrm{MRS}_{1,2}^{\mathrm{B}}} \underbrace{\partial \mathrm{F} / \partial \mathrm{x}_{1}}_{\mathrm{MRT}_{1,2}}
\end{aligned}
$$

Fig. 10.2 Welfare maximum and Pareto optimum

well known from the theory of nonlinear optimization that a saddle point $\left(x^{*}, z^{*}, \mu^{*}\right)$ of the Lagrangian function (maximum w.r.t. $x$ and $\mathrm{z}$, minimum w.r.t. $\mu$ ) at the same time characterizes a maximum $w\left(x^{*}, z^{*}\right)$ of the objective function under the restriction $F\left(x^{*}, z^{*}, \bar{y}\right) \geq 0$ (cf., e.g., Silberberg and Suen 2001, p. 432 ff.). The optimal value of the Lagrangian multiplier $\mu^{*}$ indicates by how much the optimal value of the objective function changes if the restriction is relaxed infinitesimally. The multiplication of the restriction function by the Lagrangian multiplier converts the units in which the restriction function is defined into the units of the objective function.

While the private markets in the economic sector are (at least in principle and under ideal conditions) able to implement a Pareto-efficient allocation of resources according to the main theorem of welfare economics (cf., e.g., Feldman and Serrano 2006, p. 3), this does not hold for the environmental sector where we have to face various kinds of market failure and where for many environmental goods like biodiversity, landscape beauty, etc., no markets exist at all. Therefore, the government must intervene in the environmental sector in many different ways if it wants to maximize social welfare. In this chapter, we will discuss various problems of market failure in the environmental sector and the possibilities of governments to address these problems.

When maximizing social welfare, a responsible government does not consider only the wellbeing or utility of the present generation of people but also the interests of future generations. Therefore, welfare maximization has also an intertemporal aspect which requires to ensure a sustainable development of the economy in question. We have to make sure that we pass on our planet to future generations in a state which enables also future generations to pursue their own happiness to the same extent as we do. This implies that we strive for no or only modest pollution of our environment and that we preserve a sufficient part of our natural resources for them. This is where the bioeconomy cuts in, since the transition to a bio-based economy serves the goal of resource preservation, because in the bioeconomy, the use of nonrenewable resources is substituted by the use of renewable resources. Since the bio-based economy cuts back the utilization of fossil fuels, it 
serves the goal of slowing down global warming to improve the living conditions of future generations. The bioeconomy produces also less waste than the traditional economy since many of its products can be composted naturally after use or can be reused as inputs in new production processes. Summing up, the bioeconomy serves the goals of resource saving and of reducing environmental pollution and is, therefore, in accordance with principles of sustainable development. Since private markets alone fail to serve these goals successfully, the government is called for to promote the bioeconomy in order to ensure a sustainable development of the economy.

The rest of this chapter is organized as follows: in Sect. 10.2, we will introduce the concept of sustainability which is essentially an intertemporal concept. In Sect. 10.3, we will discuss the basic principles of resource economics, i.e., the optimal use of natural resources over time, using a simple intertemporal model. Section 10.4 deals with market failure in the environmental sector and discusses various government instruments and policies to address the different kinds of market failure. Section 10.5 contains some concluding remarks.

\subsection{Sustainability}

The goal of striving for a sustainable development of society and economy is motivated by the concept of "spaceship earth". In his seminal paper on "The economics of the coming Spaceship Earth", Kenneth Boulding (1966) described our planet as a spaceship, i.e., a closed system, drifting through the outer space where no possibility exists to exchange matter between the spaceship and its environment (cf. also Spash 2013). After we will have used up all resources on our planet, we will not be able to take on board new supplies. And when we will have filled our planet up to the rim with our waste, there will be no chance to get rid of it. This notion of our planet as a spaceship where only energy, but no matter, can be exchanged with the outer space, makes it necessary to trigger a transition from what Boulding calls the "cowboy economy" ("... the success of the economy is measured by the amount of the throughput from the 'factors of production', a part of which, at any rate, is extracted from the reservoirs of raw materials and noneconomic objects, and another part of which is output into the reservoirs of pollution"-Boulding 1966, p. 11) to a "spaceman economy" ("... in the spaceman economy, throughput is by no means a desideratum, and is indeed to be regarded as something to be minimized rather than maximized. The essential measure of the success of the economy is not production and consumption at all, but the nature, extent, quality, and complexity of the total capital stock, ..."-Boulding 1966, p. 11). The basic idea of Boulding's spaceman economy is very similar to the idea of today's bioeconomy, since both are aiming for a sustainable use of scarce natural resources. Already more than 50 years ago, Boulding described his idea of a sustainable economy as follows:

In the spaceman economy, what we are primarily concerned with is stock maintenance, and any technological change which results in the maintenance of a given total stock with a lessened throughput (that is, less production and consumption) is clearly a gain. (Boulding 1966, p 11)

Looking into the literature on sustainable development, one finds a vast variety of different definitions of sustainability which often differ only in small details. These concepts can roughly be subdivided into two main categories, strong and weak sustainability, but there are also definitions of very strong and very weak sustainability, and within each category, one can find different definitions of one and the same kind of sustainability. Especially the older concepts of sustainability are defined in physical or value terms. Konrad Ott (2003) summarizes the basic idea of weak sustainability as follows:

Weak sustainability argues that what counts is the
overall value of the bequest package. Natural and
artificial capital are, in principle, substitutes.
Therefore, the depreciation and degradation of
natural capital is permissible under the idea of
intergenerational justice if artificial capital is pro-
duced at the same rate. Note that 'capital' is just
shorthand for 'means of production'. (Ott 2003,
p. 62)

Of course, it is difficult to derive practical rules for sustainable development from definitions like that, since it is not clear, e.g., by 
how much physical production capital or human capital must be built up in order to compensate for burning one ton of crude oil. Things become even more complicated if we want to follow the concept of strong sustainability, according to which natural and artificial capital are no substitutes but complements:

Strong sustainability, in contrast, emphasises that the human sphere is embedded in a natural system ('biosphere') and assumes that natural limits ought to constrain our actions. Artificial capital can only sometimes substitute for natural capital. In general, both kinds of capital are complementary. ... Strong sustainability argues in support of a constant-natural-capital rule. (Ott 2003, p. 62)

Following this concept of sustainability, each generation has to pass on a "constant-natural-capital bequest package" to the next generation, while the weak definition of sustainability requires only a "constant-overall-capital bequest package". According to the weak definition, it is possible to compensate a reduction of natural capital by building up the stock of artificial capital, while with the strong definition of sustainability, only substitution within the natural capital sector is allowed. Burning a ton of crude oil can be compensated by planting additional trees, but not by building up the production sector of the economy or by technological progress, since the overall natural capital stock has to be passed on to future generations without reduction. Like with the weak definition of sustainability, one has to ask here what the "exchange rate" between renewable (trees) and nonrenewable resources (crude oil) should be. The trade-off between different kinds of capital cannot be solved based on these definitions. Further, it is not clear why we should follow at all such physical "book-keeping" types of sustainability rules.

From a welfare economic perspective, the definition of sustainability by the World Commission of Environment and Development (1987), stated in the so-called Brundtland Report, appears to be much more plausible. Here "sustainability" is defined as

humanity's ability to ensure that it meets the needs of the present without compromising the ability of future generations to meet their own needs. (World Commission of Environment and Development 1987, p. 41)
This definition does not aim at the transfer of physical units of natural and produced capital to future generations but at the satisfaction of human needs that can be generated by using this capital. Not the transferred capital has to be constant over generations, but the satisfaction or utility it generates for different generations has to be constant. In the context of biology, this means that it is not the ecosystems that have to be counted and preserved for future generations but the ecosystem services and the utility they generate. Obviously, the Brundtland definition of sustainable development is an anthropocentric definition, while weak and strong sustainability in the traditional sense are purely physical definitions. An obvious interpretation of the Brundtland definition is that it aims at the maximization of an intertemporal social welfare function according to (10.3) where the utility functions $u_{t}$ are interpreted as the level of satisfaction of different generations. This leads us to the next section of this chapter where we will briefly discuss the principles of intertemporal welfare maximization with a limited and nonrenewable resource stock.

\subsection{Welfare Maximization with Nonrenewable Natural Resources}

In this section, we consider the optimization problem of a government that wants to maximize social welfare over different generations in the sense of a sustainable development. For simplicity's sake, we assume that in this economy, there prevails perfect information with a uniform interest rate for lending and borrowing. We further assume that society is equipped with a given stock $R$ of a nonrenewable resource which can be consumed directly after extraction, i.e., there is no further refinement or production process between extraction and consumption of this resource. This kind of model is also known as the "cake-eating" model of nonrenewable resources. The government is supposed to maximize social welfare over $T_{s}+1$ generations or time periods $t=0,1,2, \ldots, T_{s}$. We assume that the utility of each generation depends on its 
consumption $x_{t}$ of the resource $R$ where overall consumption of all generations is restricted by the constraint

$$
\sum_{t=0}^{T_{s}} x_{t} \leq R
$$

The government maximizes the intergenerational welfare function

$$
\begin{array}{r}
W=\quad w\left(u_{0}\left(x_{0}\right), u_{1}\left(x_{1}\right), \ldots, u_{T_{s}}\left(x_{T_{s}}\right)\right) \\
\left(\frac{\partial w}{\partial u_{t}}>0\left(t=0,1, \ldots, T_{s}\right)\right)
\end{array}
$$

under restriction (10.2). The respective firstorder Kuhn-Tucker conditions are shown in Fig. 10.3.

Applying the interpretation of the Lagrangian multiplier $\mu^{*}$ according to function $L$ above to our optimization problem in Fig. 10.3, we find that $\mu^{*}$ indicates by how much maximum attainable social welfare increases if the restriction parameter $R$ is increased by one unit. Therefore, $\mu^{*}$ expresses the marginal social value of the resource stock $R$ or its shadow price (cf., e.g., Silberberg and Suen 2001, p. 167). From condition (i), it follows that $\mu^{*}$ is positive if the marginal welfare of consumption $\frac{\partial w}{\partial u_{t}} \cdot \frac{\partial u_{t}}{\partial x_{t}}\left(x^{*}\right)$ is positive for at least one generation $t$. In this case, the resource will be completely depleted after generation $T_{s}$ according to condition (iv). From condition (ii), it follows that maximizing intergenerational welfare implies a resource allocation such that for all generations with a positive consumption $x_{t}$, marginal overall welfare is the same for all generations:

$$
\begin{aligned}
\frac{\partial w}{\partial u_{t}} \cdot \frac{\partial u_{t}}{\partial x_{t}}\left(x^{*}\right)= & \frac{\partial w}{\partial u_{t}^{\prime}} \cdot \frac{\partial u_{t^{\prime}}}{\partial x_{t^{\prime}}}\left(x^{*}\right) \\
& \times\left(t, t^{\prime} \in\left\{0,1, \ldots, T_{s}\right\}\right)
\end{aligned}
$$

\section{Shadow Price}

A shadow price is a hypothetical or virtual price that is never actually paid. Like a market price, it indicates the marginal value of a good or resource, but this good or resource is not traded in markets, and, therefore, the shadow price is only of theoretical importance.

From (10.4), we can see that generations with a high welfare weight $\partial w / \partial u_{t}$ will be granted higher consumption quantities $x_{t}$ (because of the diminishing marginal utility of consumption $\left.\partial^{2} u_{t} /\left(\partial x_{t}\right)^{2}<0\right)$, while generations which are considered less important by the central planner
Fig. 10.3 Welfare maximization with a nonrenewable resource

\section{Lagrangian:}

$$
\mathbf{L}(\mathbf{x}, \mu)=\mathbf{w}\left(\mathbf{u}_{0}\left(\mathbf{x}_{0}\right), \mathbf{u}_{1}\left(\mathbf{x}_{1}\right), \ldots, \mathbf{u}_{\mathrm{T}_{\mathbf{S}}}\left(\mathbf{x}_{\mathrm{T}_{\mathbf{S}}}\right)\right)+\mu \cdot\left(\mathbf{R}-\sum_{\mathbf{t}=0}^{\mathrm{T}_{\mathrm{S}}} \mathbf{x}_{\mathbf{t}}\right)
$$

First-order conditions:

$$
\begin{aligned}
& \text { (i) } \frac{\partial \mathbf{L}}{\partial \mathbf{x}_{\mathbf{t}}}\left(\mathbf{x}^{*}, \mu^{*}\right)=\frac{\partial \mathbf{w}}{\partial \mathbf{u}_{\mathbf{t}}} \cdot \frac{\partial \mathbf{u}_{\mathbf{t}}}{\partial \mathbf{x}_{\mathbf{t}}}\left(\mathbf{x}^{*}\right)-\mu^{*} \leq \mathbf{0} \quad\left(\mathbf{t}=\mathbf{0}, \ldots, \mathbf{T}_{\mathbf{s}}\right) \\
& \text { (ii) } \frac{\partial \mathbf{L}}{\partial \mathbf{x}_{\mathbf{t}}}\left(\mathbf{x}^{*}, \mu^{*}\right) \cdot \mathbf{x}_{\mathbf{t}}^{*}=\left(\frac{\partial \mathbf{w}}{\partial \mathbf{u}_{\mathbf{t}}} \cdot \frac{\partial \mathbf{u}_{\mathbf{t}}}{\partial \mathbf{x}_{\mathrm{t}}}\left(\mathbf{x}^{*}\right)-\mu^{*}\right) \cdot \mathbf{x}_{\mathbf{t}}^{*}=\mathbf{0} \\
& \text { (iii) } \frac{\partial \mathbf{L}}{\partial \mu}\left(\mathbf{x}^{*}, \mu^{*}\right)=\mathbf{R}-\sum_{\mathbf{t}=\mathbf{0}}^{\mathbf{T}_{\mathbf{s}}} \mathbf{x}_{\mathbf{t}}^{*} \geq \mathbf{0} \\
& \text { (iv) } \frac{\partial \mathbf{L}}{\partial \mu}\left(\mathbf{x}^{*}, \mu^{*}\right) \cdot \mu^{*}=\left(\mathbf{R}-\sum_{\mathbf{t}=\mathbf{0}}^{\mathbf{x}_{\mathbf{s}}} \mathbf{x}_{\mathrm{t}}^{*}\right) \cdot \mu^{*}=\mathbf{0} \\
& \text { (v) } \mathbf{x}_{\mathbf{t}}^{*} \geq \mathbf{0}\left(\mathbf{t}=\mathbf{0}, \ldots, \mathbf{T}_{\mathbf{s}}\right) \quad, \mu^{*} \geq \mathbf{0}
\end{aligned}
$$


are given lower consumption quantities. If all generations have the same importance for government so that

$$
\frac{\partial w}{\partial u_{t}}=\frac{\partial w}{\partial u_{t^{\prime}}}\left(t, t^{\prime} \in\left\{0,1, \ldots, T_{s}\right\}\right)
$$

it follows from (10.5) that the resource is distributed over the different generations such that their marginal utility of consuming this resource is the same for all generations:

$$
\frac{\partial u_{t}}{\partial x_{t}}\left(x^{*}\right)=\frac{\partial u_{t^{\prime}}}{\partial x_{t^{\prime}}}\left(x^{*}\right)\left(t, t^{\prime} \in\left\{0,1, \ldots, T_{s}\right\}\right)
$$

This corresponds closely with the definition of sustainability by the Brundtland Report "Our Common Future" stated above. This principle of a sustainable development has reached enormous prominence not only among scientists but also among politicians and broad parts of the public. It forms the guideline for most political negotiations on environmental preservation and climate policy. Condition (10.6) is, of course, a marginal criterion which does not imply that each generation should be able to consume the same quantity of natural resources as, e.g., the strong sustainability criterion requires. It is an anthropocentric criterion which aims at the (marginal) satisfaction of the needs of people and not at the resources at their disposal.

Viewed in the context of a more general setting criterion, (10.6) can be interpreted as an encouragement of the transition from a fossilbased to a bio-based economy. Differently from the strong and weak criteria explained above, sustainability in the sense of (10.6) is defined in terms of utility, no matter from which resource this utility is derived. If fossil resources become scarcer or are not available at all from some generations on, we have to make sure that this generation has substitutes for these fossil resources at their hands to guarantee the fulfillment of condition (10.6). This will be possible only after we will have developed new technologies which can produce the same satisfaction of human needs from renewable or bio-based resources that we enjoy today from the consumption of fossil resources. Therefore, the transition of our economy to a bio-based economy can be interpreted as an immediate consequence of the maximization of an intergenerational social welfare function.

\subsection{Market Failure in the Environmental Sector and Government Policy for a Bio-Based Economy}

The bioeconomy aims not only at the preservation of natural resources for future generations but also at an optimal management of the environmental sector for the present generation. Therefore, we will focus on a comparative static analysis of the interaction between the economy and the environment in this section, instead of an intertemporal analysis as in the previous section. First of all, the question arises what we understand by an "optimal" management of the environmental sector. In Sect. 10.1, we learned that the government is expected to maximize a social welfare function as a strictly monotonically increasing function of the individual utility functions of all citizens, where each of these utility functions is strictly monotonically increasing in market consumption $x$ and environmental quality $z$. In Fig. 10.2, we saw that a welfare maximum implies the realization of a Pareto optimum. The difference between the two concepts is that the welfare maximum also considers the distributional justice ideals of government as represented by the welfare weights $\partial w / \partial u_{h}$, while a Pareto optimum is a pure efficiency criterion. For each economy, there exists an infinity of different Pareto-optimal allocations each of which implies a different distribution of individual well-being or utility. Based on the welfare weights $\partial w / \partial u_{h}$, the government chooses one of these Pareto optima for a welfare maximum. Since we are not interested in distributional issues here and since the welfare weights $\partial w / \partial u_{h}$ cannot be determined on scientific grounds anyway, we concentrate on the implementation of Pareto-optimal allocations of $x$ and $z$ in this section. Our main interest here is if 
private markets, when left alone, are able to implement a Pareto optimum without any government intervention. If this is not the case, we speak of market failure.

\section{Public Goods}

From Fig. 10.2 we saw that a Pareto optimum requires that the marginal rates of substitution (MRS) between any pair of two market goods are equal for all households and equal to the marginal rate of transformation (MRT) between these two market commodities. The economic interpretation of this condition is that in a Pareto optimum, the marginal utility of consuming a market commodity (in relation to the marginal utility of some other market commodity) is equal for all consumers and is also equal to the marginal production cost of that commodity (in relation to the marginal production cost of the other market commodity). Therefore, no reallocation of consumption or production could lead to a utility increase of one consumer without reducing the utility of some other consumer. Because of the rivalry property of market goods, each unit of a market good can be consumed by one person only. Therefore, the individual marginal utility of consuming a market good equals the "social" marginal utility accruing from that good, so that our conditions in Fig. 10.2 say that in a Pareto optimum, the social marginal utility of consuming a market good should be equal to its social marginal cost.

We could also see in Fig. 10.2 that the sum of the marginal rates of substitution between a market good $x$ and an environmental public good $z$ equals the marginal rate of transformation between the market good $x$ and the environmental good $z$. This optimality condition follows from the fact that in Fig. 10.2 we assumed that $z$ is a pure public good. While market goods are characterized by the criterion of rivalry in consumption and the exclusion principle, these criteria are not fulfilled for public goods like clean air, the climate in a specific region, biodiversity, etc. The economic interpretation of the optimality condition in Fig. 10.2 says that in a Pareto optimum, the sum of the marginal utilities of consuming the public good (in relation to the marginal utility of consuming some market good) should equal the marginal production cost of the public good (in relation to the marginal production cost of that market good). Because of the non-rivalry of public goods, all households consume the same quantity and quality of such a good simultaneously. Therefore, the social marginal utility accruing from the consumption of a public good equals the sum of the individual marginal utilities. The optimality condition in Fig. 10.2, therefore, says that in a Pareto optimum, the social marginal utility should equal the marginal production cost. This is, in principle, the same condition that holds for market goods. The difference between both conditions is that the social marginal utility of consumption equals the individual marginal utilities for a market good and the sum of the individual marginal utilities for a public good.

Since the consumption of a public good is non-rival and since the exclusion principle fails, there is no incentive for private agents to invest in the provision of a public good because they will not be able to earn their money back. If all households were willing to pay a price for the consumption of a public good according to their marginal utility of consuming that good, an optimal provision of public goods in the sense of our optimality condition would be feasible. But, again, the non-rivalry in consumption and the failure of the exclusion principle make such a so-called Lindahl solution (s. Lindahl 1919) impossible. Private consumers have no incentive to pay for enjoying the public goods since they cannot be prevented from consuming it for free without even compromising its quality. Therefore, free riding is the optimal strategy for a strictly rational "homo oeconomicus", and, as a consequence, nobody will be willing to invest in the provision of a public good.

Though we know that psychological motives like altruism, social norms, the need for social approval, etc., set incentives also for a private provision of public goods, these effects will not be strong enough to trigger a Pareto-optimal provision, at least not with larger groups of people. Therefore, governments have to intervene to ensure a sufficient, if not optimal, provision of 
public goods. This is why the transition to a bio-based economy, which serves the goal of providing the public good "world climate" in a sustainable quality, will not happen without government support.

\section{Common-Pool Goods}

In the context of environmental protection and sustainability, the group of so-called commonpool goods plays an important role. These are goods which are rival in consumption, so that their quality is diminished when they are consumed (i.e., the marginal utility of consuming them is the smaller the more people are consuming them), while nobody can be excluded from utilizing them. Because of this combination of rivalry in consumption and the failure of the exclusion principle, rational individuals will consume as much as possible of such a good as fast as possible. The dominance of this consumption strategy will lead to what Garrett Hardin (1968) called the "tragedy of the commons", i.e., a fast overuse of such resources which will lead to their premature extinction, if the government does not intervene. Examples of common-pool goods suffering from this kind of market failure are fish stocks in the open sea where everybody can catch as much as he desires, but also groundwater aquifers, rivers, or lakes which are exploited by different private parties or different countries, rain forests in countries where no government regulation for their exploitation is enforced, etc. Without strict utilization regimes which are enforced by governments, these resources will be lost within a short time. Besides setting up strict utilization schemes for such goods, the government can support their preservation also by encouraging the provision of alternative commodities serving the same purpose as the common-pool goods. In the case of endangered fish stocks, the government can, e.g., support financially the development of new kinds of marine food like algae-based nutrition. This branch of the bioeconomy has been flourishing over the past years, but this development has been possible only because of government subsidies. Therefore, the bioeconomy depends on government intervention also with respect to the preservation and sustainable provision of common-pool goods.

\section{Externalities}

The most important cause of market failure in the environmental sector is the existence of so-called external effects. An external effect exists, if an economic activity of one economic agent (household or firm) has an impact on another economic agent's objective function (e.g., a utility function or profit function) where this agent has no control over the effect. If the external effect is positive, we speak of an external benefit; if it is negative, it is called an external cost. Especially external costs are responsible for the deterioration of environmental quality. Examples are the pollution of air, soil, and water as a by-product of the production or consumption of market goods. If a river or lake or a groundwater aquifer is polluted by the toxic wastewater of a production plant, this has consequences for the profits of other firms (e.g., fishermen living at the same lake or river or producers of mineral water from that aquifer), but also households using that lake for recreation or receiving their drinking water from that groundwater aquifer are affected. Without government regulations, they have no possibilities to influence the extent of pollution or to stop it. But also households can cause externalities affecting other households (e.g., car driving leading to particulate matter pollution in our cities) or firms (e.g., by burning garden rubbish in the neighborhood of a hotel or an open-air restaurant). Households and firms together cause negative externalities on the world climate by releasing carbon dioxide into the atmosphere, thereby affecting the profit functions of producers (e.g., farmers) and the utility functions of households all over the world. The bioeconomy addresses especially this problem by developing new alternative products and new technologies which use less carbon-based inputs and cause less $\mathrm{CO}_{2}$ emissions than traditional production processes. Markets alone ignore the existence of external costs and benefits since the prices of market commodities equal the marginal utility of households consuming these commodities on 
the one hand and the marginal production cost of producers on the other. The external costs of production in the form of pollution are borne by society as a whole, but no price is charged for them, as long as we live in a laissez-faire economy with no government intervention. Therefore, we have a situation here where the bioeconomy, which leads to a reduction of external costs, will not develop without government support, since the development of bioeconomic production technologies is costly and nobody will be willing to pay for it voluntarily.

If the government decides to reduce negative externalities (and to boost positive externalities), the question arises which level or extent of externalities is optimal. Reducing, e.g., pollution accruing from the production of market goods to zero would in many cases mean that also the production of these goods would be reduced to zero, which probably would not be optimal for society. Economic intuition would advise us to apply the Pareto optimality rule derived above in Fig. 10.2 also to the present problem. This would mean to expand the production of a market good that causes a negative (positive) externality up to the point where the social marginal benefits accruing from that commodity equal its marginal social cost. The marginal social cost consists of the marginal production cost plus the marginal external costs imposed on society as a whole, while the social marginal benefits consist of the individual marginal consumption benefits plus the marginal external benefits.

Our intuition is confirmed if we solve the optimization problem leading to a Pareto optimum with external effects as shown in Fig. 10.4. As before, we deal here with an economy with two households $A$ and $B$, two market goods $x_{1}$ and $x_{2}$, and an externality $\mathrm{s}$ accruing from the consumption (or production) of commodity 1. The externality affects the wellbeing of both households. In the case of a negative externality, good 1 could be, e.g., car driving leading to air pollution with particulate matter. A positive externality could accrue from using electric cars by both households, which would lead to less air pollution and less noise.

The conditions for a Pareto optimum with externalities are shown in Fig. 10.5. The first three terms correspond with the optimality conditions for market goods as known from Fig. 10.2. The numerator of the last term captures the marginal external costs or benefits accruing from commodity $1 . \partial s / \partial x_{1}$ is the marginal effect of consuming one more unit of commodity 1 (e.g., driving one more kilometer by car) on the externality (e.g., PM pollution), while the term in parentheses expresses the overall effect
Fig. 10.4 Pareto optimum Pareto efficiency with externalities with externalities

$$
\max u^{A}\left(x_{1}^{A}, x_{2}^{A}, s\left(x_{1}^{A}+x_{1}^{B}\right)\right) \text {, }
$$

Constraints: $u^{B}\left(x_{1}^{B}, x_{2}^{B}, s\left(x_{1}^{A}+x_{1}^{B}\right)\right) \geq U^{B} ; F\left(x_{1}^{A}+x_{1}^{B}, x_{2}^{A}+x_{2}^{B}, \bar{y}\right) \geq 0$

Lagrangian: $L\left(x_{1}^{A}, x_{2}^{A}, x_{1}^{B}, x_{2}^{B}, \mu, v\right)=u^{A}\left(x_{1}^{A}, x_{2}^{A}, s\left(x_{1}^{A}+x_{1}^{B}\right)\right)$

$$
+v\left[u^{B}\left(x_{1}^{B}, x_{2}^{B}, s\left(x_{1}^{A}+x_{1}^{B}\right)\right)-u^{B}\right]+\mu F\left(x_{1}^{A}+x_{1}^{B}, x_{2}^{A}+x_{2}^{B}, \bar{y}\right)
$$

Fig. 10.5 Pareto optimality conditions with externalities

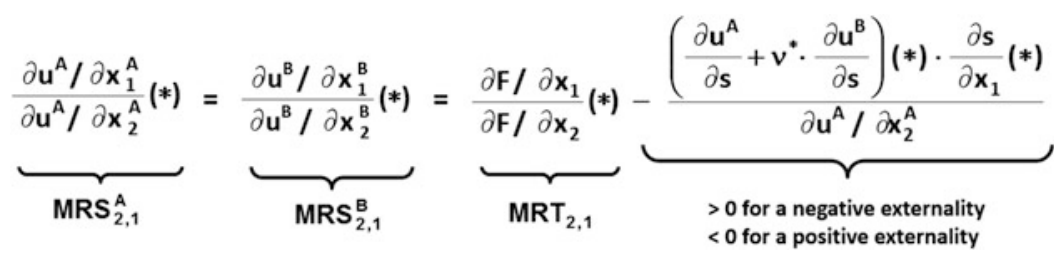


of one more unit of the externality on the wellbeing of all households. The last term drives a wedge between the marginal rate of substitution between commodities 1 and 2 on the one hand and the marginal rate of transformation on the other. Considering external costs explicitly leads to a new Pareto-optimal allocation where the MRT is smaller than the MRS of the households, while the existence of external benefits require an allocation where the MRT is larger than the MRS of the households.

If a Pareto-optimal allocation according to Fig. 10.5 is to be implemented in a market economy, this can be done, e.g., by imposing a uniform per-unit tax on a commodity causing external costs (or by granting a uniform per-unit subsidy on commodities causing external benefits). The price a household would have to pay for a commodity causing a negative externality would then comprise the marginal production cost of that commodity plus the marginal external cost in terms of the tax. If this tax amount equals exactly the external costs, it is called a Pigovian tax (cf. Pigou 1920 or Sandmo 2008). It will implement a Pareto-optimal allocation. In practice it will not be possible to assess the exact amount of such a tax since the necessary information, especially the marginal utilities of households (cf. Fig. 10.5), is not available. Therefore, the Pigovian tax represents a theoretical ideal only. A practical instrument for the reduction of a negative externality is the so-called pricing and standards approach (PSA), suggested by Baumol and Oates (1971). The PSA recommends to impose a uniform per-unit tax on goods causing negative externalities because this will lead to a more efficient allocation than in the initial situation with a minimum of overall abatement costs. In the case of externalities caused by $\mathrm{SO}_{2}$ or $\mathrm{CO}_{2}$ emissions, an analogous effect can be reached by introducing an emission trading system, where emitters have to pay a uniform price per unit of the respective emission. Reducing pollution by regulatory or command-andcontrol policy, where certain emission caps are defined by government and any transgression of these emission limits will be prosecuted, leads also to a reduction of negative externalities but not with minimum abatement costs like with emission taxes according to the PSA or the Pigovian tax approach.

Since with emission taxes or a cap-and-trade policy polluters have to pay for every single ton of emissions, i.e., for every unit of a negative externality, there exists always an incentive to develop new abatement technologies to reduce the emission costs. Therefore, the taxation of negative externalities (external costs) and the subsidization of positive externalities (external benefits) are important instruments to trigger the transition from a fossil-based to a bio-based economy with minimum overall cost.

\subsection{Concluding Remarks}

In this chapter, it has been argued that the government is responsible for environmental management in an economy and, especially, for the organization of the transition from a fossil-based to a bio-based economy. The existence of various causes of market failure in the environmental sector prevents the implementation of a Paretoefficient allocation of environmental resources without the help of government. In an intertemporal context, an optimal allocation of a nonrenewable natural resource requires the maximization of an intergenerational social welfare function where the interests of the different generations are considered in form of their utility functions. Private markets alone will only consider the wellbeing of the present generation and, maybe, also of the next. Neglecting the interests of all following generations prevents a sustainable use of such resources in the sense of the Brundtland definition. In a comparative static context, the existence of public goods, commonpool goods, as well as of external costs and benefits of market consumption and production lead to market failure in the sense that without government intervention the implementation of a Pareto-optimal resource allocation will not be possible. The principles and conditions of such an optimal resource allocation were derived, and different instruments for their practical implementation were discussed in this chapter. 


\section{Review Questions}

- Why is government responsible for the preservation of the environment in general and, especially, for the development of the bioeconomy?

- Which are the most important concepts of sustainability? What are their main characteristics?

- Please explain the characteristics of the so-called cake-eating model of intertemporal resource use and its relation to the concept of very weak sustainability.

- What are the main reasons for market failure in the environmental sector and which are the most important instruments of government policy in this context?

- What are the causes of the so-called tragedy of the commons?

- Why is the government responsible for the provision of public goods? What could be the incentives for private people to contribute to the provision of public goods?

- Please explain the first-order conditions for a Pareto-optimal regulation of external effects.

- What is the significance of the concept of shadow prices in the context of environmental policy?

\section{References}

Baumol WJ, Oates WE (1971) The use of standards and prices for environmental protection. Swed J Econ 73, pp 42-54

Boulding KE (1966) The economics of the coming spaceship earth. In: Jarrett $\mathrm{H}$ (ed) Environmental quality in a growing economy. John Hopkins University Press, Baltimore, pp 3-14

Feldman AM, Serrano R (2006) Welfare economics and social choice theory, 2nd edn. Springer, New York

Hardin G (1968) The tragedy of the commons. Science 162 (3859), pp 1243-1248

Lindahl E (1919) Just taxation-a positive solution. In: Musgrave R, Peacock A (eds) Classics in the theory of public finance, 1st edn. Macmillan, London, pp 98-123

Ott K (2003) The case for strong sustainability. In: Ott K, Thapa P (eds) Greifswald's environmental ethics. Steinbecker, Greifswald, pp 59-64

Pigou AC (1920) The economics of welfare. Macmillan, London

Sandmo A (2008) Pigouvian taxes. The new Palgrave dictionary of economics, 2nd edn. Palgrave Macmillan, London

Silberberg E, Suen W (2001) The structure of economics: a mathematical analysis. McGraw-Hill, New York

Spash CL (2013) The economics of Boulding's spaceship earth. In: Dolfsma W, Kesting S (eds) Interdisciplinary economics: Kenneth E. Boulding's engagement in the sciences. Routledge, London, pp 348-363

World Commission of Environment and Development (1987) Our common future. Oxford University Press, Oxford

Open Access This chapter is licensed under the terms of the Creative Commons Attribution 4.0 International License (http://creativecommons.org/licenses/by/4.0/), which permits use, sharing, adaptation, distribution and reproduction in any medium or format, as long as you give appropriate credit to the original author(s) and the source, provide a link to the Creative Commons license and indicate if changes were made.

The images or other third party material in this chapter are included in the chapter's Creative Commons license, unless indicated otherwise in a credit line to the material. If material is not included in the chapter's Creative Commons license and your intended use is not permitted by statutory regulation or exceeds the permitted use, you will need to obtain permission directly from the copyright holder. 